\title{
Research on the Internet's Impact on Tourism Distribution Channels in the Era of Smart Tourism
}

\author{
Fengyun Wei \\ History College of Changchun Normal University Changchun, Jilin China 130032 \\ wfyleh@163.com
}

\begin{abstract}
Keywords: Smart tourism; Internet; Tourism distribution channels; Information technology
\end{abstract}
\begin{abstract}
In the era of Smart Tourism, the Internet of which the essence lies in the information dissemination inevitably affects the tourism distribution channels. This paper mainly analyzes the Internet's impact on the structure and the function of tourism distribution channel, holding that the Internet information technology is not only the incentive but also an important way for the changes of the function of tourism distribution channel. Then this paper points out the deficiencies of the current research about the Internet's impact on tourism distribution channels and points out that, in the era of Smart Tourism which mainly features in personalized, ubiquitous and convenient travel information services, the Internet big data can provide new tools, new methods and new paradigm for the strategy development of tourism distribution channel.
\end{abstract}

\section{Introduction}

It is well known that information technology is the lifeblood of tourism industry. The importance of information technology for travel and tourism industry has been widely recognized. However, information technology has never been so closely intertwined with tourism experience, especially with the rapid growth of the search engine, the expansion of the online distribution channels, the establishment of the virtual community and the emergence of more and more social media platforms, tourism information technology has permeated every level of tourism and comprehensively expanded the technical level of tourism. In fact, the popularity of mobile information technology, especially the integration of smart phones and information search, communication, entertainment and social contact, can pass the information timely to the tourists on the way, which further improves the tourism experience [1]. The technology application of virtual reality, augmented reality, and artificial intelligence and so on in tourism scene further prompted the tourism experience to reach to the level of "peak experience". With the development of cloud computing and the so-called Internet of Things, today's information technology environment is increasingly ubiquitous, intelligent and situational awareness. There are many arguments shows that we have entered the era of Smart Tourism, which mainly features in personalized, ubiquitous and convenient travel information services [2].

The essence or the nature of the Internet is information dissemination. Tourism industry is a kind of information-intensive industry and information-dependent industry [3]. The primary function of tourism distribution channels is to provide information and promote trade. Internet inevitably affects the tourism distribution channels, mainly in two aspects:

\section{Internet's Impact on the Structure of Tourism Distribution Channels}

Among the studies on the Internet's, impact on tourism distribution channels most of which pay attention to the influence on the structure of tourism distribution channels, including the judgment of future development trend of tourism distribution channels: disintermediation and re-intermediation. Disintermediation refers to that the Internet replace the middlemen (especially the traditional middlemen) in distribution function. The so-called re-intermediation refers to that the middlemen taking advantage of the convenience provided by the Internet, recombine their original function and mechanism and continue to play their unique advantages in the tourism distribution channels. 
On the one hand, because of the Internet, the disintermediation phenomenon in tourism distribution channels will appear, that is the role of travel agents and travel wholesalers in the western travel agency system has greatly been reduced and at the same time these travel agents and travel wholesalers will continue to shrink because of the extrusion from the new tourism intermediaries based on the Internet.

On the other hand, the Internet information technology also brought the re-intermediation opportunity to the tourism distribution channels. The traditional travel agencies or travel agents reduce the cost, restructure the business process through the rational utilization of information technology, giving full play to the advantages of travel agency or the travel agent's core business: select market segments, provide personalized service products, etc. and get living space and change the operation mode of traditional travel agents through their own reforms. In addition, the new web-based online travel intermediaries, with diversified business mode and trading platform, has further enriched the structure of tourism intermediary and at the same time transformed the tourism distribution channels and formed a new distribution channel model (figure 1) in the era of new Internet technology. As can be seen from the model, the tourism distribution channel structure has become more complicated under the influence of the Internet.

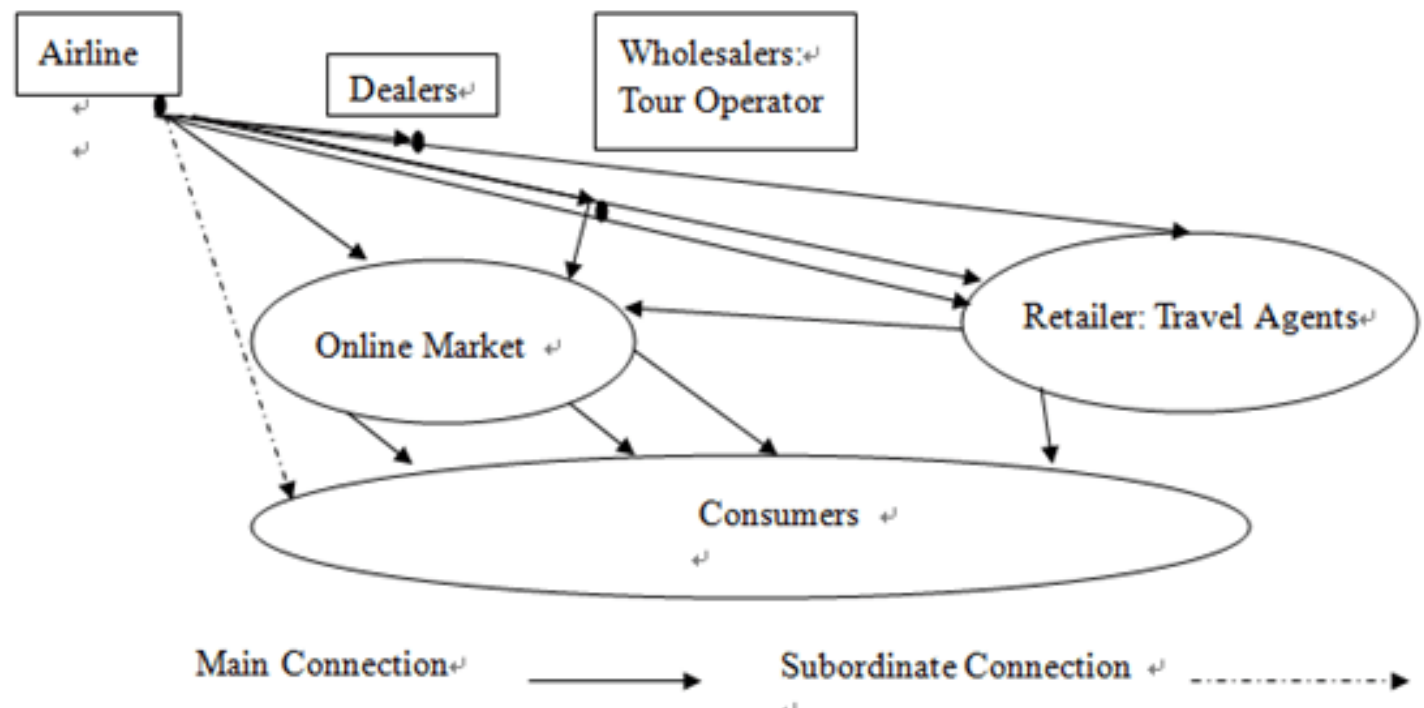

Figure1.The tourism distribution channel model under the influence of the Internet

\section{Internet's Impact on the Function of Tourism Distribution Channels}

As a kind of information technology, the Internet has greatly changed the way of information dissemination and exchange, and gradually developed into a kind of direct sales channel path, which requires the tourism distribution to transform its function [4].

A recent research on American tourists shows that the Internet continues to be the first information source when tourists making travel plan and it also shows that when tourists look for and prepare for the future tourism experience, they are highly dependent on information technology [5]. Now the tourists have realized that compared to other tools, the Internet is the indispensable tool to help them to make destination, catering and shopping choices. At the same time, the consumers get more identification with the security and personalized services of the Internet. With the popularity of the intelligent mobile phones, tourists are able to use the Internet anytime and anywhere, which has a profound impact on their information search and plan making behavior [6]. It is thus obvious that the Internet has redefined how the tourists find and purchase tourism products, which has changed the distribution of tourism products, making the combination of tourism product design more personalized. 
For the distribution channel members, the Internet information technology has gradually reconstructed the business process of all the enterprises' in the distribution channels, so that they must redefine their core competitiveness. Internet-based electronic intermediary (E-intermediary) has changed the traditional distribution strategies with one after another business model and gradually demonstrated that trading convenience is more important than the product selectivity. The new generation of tourists becomes more flexible in searching information.

Those marketing subject that gain the tourists' recognition and maintain a long-term contact with them will get more and more attention, in return, a new generation of tourists expect special services such as private ordering service. When they achieve psychological balance, their attention to information reach the top and that is the so-called "peak travel experience". In order to reach this level, the new generation of tourism consumers are increasingly looking for the travel experience information, which is personalized, emotional, and interesting, in order to understand the new tourism products. As a result, the Internet and other information technology will transfer the travel distribution function from the information dissemination and exchange to professional mechanism that increases additional value and service, which makes information exchange quicker and easier, booking mechanism more complicated and at the same time service providing perfect.

It is thus obvious that the Internet information technology is not only the incentive but also an important way for the changes of the function of tourism distribution channel. However, the application of the Internet information technology is different in different business category, different type of destinations and different tourism product market for the travel distribution channel members [7].

\section{The Deficiency of the Existing Research and Prospects on This Issue}

The existing research on the change of Internet's impact on tourism distribution channels are mostly from the static perspective to analyze the status quo of tourism distribution channels, to describe the influence of the Internet, ignoring the specific process and the key points of the impact from the Internet. Likewise, the research on the focus object is lack of overall analysis based on channel system. Objectively speaking, it is difficult to have a whole grasp of the travel distribution system because of the separation of the involved area. However, expanding the perspective from mostly suppliers and middlemen perspective to a destination perspective is one of the ways to solve the problems of research scope and perspective, which not only can gather the range of observations in unity but also can provide the whole analysis framework for the destination-based system. At the same time, we should expand the research object that is to study the tourism distribution channel and its change's impact on the destination, which is relatively deficiency in the current research on the tourism distribution channel and its change.

In addition, it is important to note that the development of the Internet actually affected the behavior relationship among travel distribution channel members. Prior to the development of the Internet popularization, suppliers almost had no choice but to use middlemen. Based on the invisibility of tourism products, intermediaries and final consumers are very dependent on the accuracy and timeliness of information, thus tourism distribution channel members have been divided into different grades because of the different information they get. The development of the Internet has changed the situation of information distribution, so it is bound to affect the relationship among the tourism distribution channel members. Under the influence of the Internet, the emergence of a new distribution channel path will give the tourism distribution channel members what kind of effects, whether there will be a mutual promotion or a restriction role among members, which are issues worthy of further study.

\section{Conclusion}

Today's consumers of mobile and geographic information technology become the era of sensor through the interaction with digital system and data created during the trip [8]. In particular, the network and mobile application system, which focus on visitors' schedule, create a huge 
consumption data [9]. Tourism big data makes the allocation of tourism resource more reasonable. By analyzing big data tourism enterprises can identify tourists' activity form and preferences, find potential customers and provide better-personalized service to the existing customers. The emergence of big data enables enterprises to promptly and dynamically identify visitors' activity patterns and preferences. The focus of enterprise competition is transferred from the product innovation to organizing the potential consumers, to guiding and inspiring consumers' demand, to providing support for a variety of new destination to establish the competitive advantage. Big data also creates a new kind of marketing mode dominated by consumer by raising the intelligent consumption and improving the business process. In the era of big data, new tourism enterprises rise rapidly, the development speed of overall tourism industry become faster, industry positioning are more accurate, industry convergence speed is higher and cross-border industry increase, all of which are the important development trend of the tourism industry[10]. Ultimately, the Internet big data provide new tools, new methods and new paradigm for the strategy development of tourism distribution channel in the era of Smart Tourism.

\section{Acknowledgements}

This research is supported by Humanities and Social Science Fund Project of Education Department of Jilin Province " Research on the Overall Construction of the Smart Tourism of Jilin Province" (code: 2015280) and Humanities and Social Science Fund Project of Changchun Normal University "Construction Mode Study on the Smart Tourism of Jilin Province " (code: 2014003).

\section{References}

[1] Tussyadiah I. P. and Zach F. J.: Annals of Tourism Research, Vol.39 (2012) No.2.p. 780-800.

[2] M.Y.Wu and K.J.Huang: Tourism Tribune, (2014) No.12.p. 66- 74. (In Chinese)

[3] Gretzel U.: Annals of Tourism Research, Vol.38 (2011) No.3.p.757-779.

[4] Lewis D. and Bridger D.: The Soul of the New Consumer: Authenticity-What We Buy and Why in the New Economy (Nicholas Brealey Publishing, America 2011).

[5] Z.Xiang, D.Wang and O'Leary J.T.: Journal of Travel Research, Vol.54 (2015) No.4 .p.511-527.

[6] D.Wang, Z. Xiang and Fesenmaier D. R.:Annals of Tourism Research, 48(2014) No.2.p. 11-26.

[7] Benkendorff P.,Sheldon P. and Fesenmaier D.R.: Tourism Information Technology (the 2nd Edition) (CABI, London 2015).

[8] Goodchild M.F.: Geo Journal, Vol.69 (2007) No.4.p. 211-221.

[9] X.Guo: Computer Knowledge and Technology, Vol.14 (2013) No.5.p. 32-36.(In Chinese)

[10]P.S.Zhang: Reformation \& Strategy, (2014) No.9.p. 110-114. (In Chinese) 